\title{
« L'apport du nouveau code foncier en matière de résolution des conflits au Burundi ».
}

\author{
Par Emery Nukuri ${ }^{1}$
}

INTRODUCTION ET CONTEXTE.

D'une superficie de $27834 \mathrm{~km}^{2}$ 2, le Burundi est un pays enclavé situé dans la région des Grands Lacs et entouré par la République démocratique du Congo à l'ouest, le Rwanda au nord, et la Tanzanie à l'est et au sud. La population du Burundi est estimée à 8.053.574 habitants, soit une densité moyenne de $310 \mathrm{hab}$. $/ \mathrm{km} 2$. L'accroissement annuel de la population est estimé à $3 \%{ }^{3}$. Jusque maintenant, le Burundi connait une dépendance particulièrement forte à la terre ${ }^{4}$ parce que $90 \%$ de la population Burundaise dépend directement des ressources tirées de la culture de la terre ${ }^{5}$. Pour reprendre..il sied de soutenir que, « sans terre, la vie est impossible $»^{6}$.

Sous la période précoloniale, les terres du Burundi appartenait au Mwami. Les autres burundais n'en étaient que des usagers. La société Burundaise traditionnelle considérait la terre comme un patrimoine collectif inaliénable administré par le Mwami et ses délégués sur base du droit coutumier ${ }^{7}$. Pendant la période coloniale, la colonisation allemande

1 Emery Nukuri est Assistant à la Faculté de droit U.B et doctorant en droit des biens à la Katholieke Universiteit Leuven (adresses mail : kuriemery@yahoo.fr ou emery.nukuri@kuleuven-kulak.be).

2 République du Burundi, Premier rapport de mise en application de la Charte Africaine des droits de l'homme et des peuples, Bujumbura, septembre 2010, p 6.

3 Idem, p.2.

4 République du Burundi- Lettre de politique foncière de 2008, § 2 : « Alors que le Burundi compte déjà parmi les pays les plus densément peuplés du monde, la pression foncière s'amplifie encore. Le pays connaît une croissance démographique sans précédent. Par ailleurs, le retour de réfugiés de longue date s'effectue dans un contexte difficile, dans la mesure où, dans de nombreux cas, la plupart de leurs terres ne sont plus vacantes. Des cessions et concessions irrégulières de terres domaniales viennent ajouter à la confusion ».

5 République du Burundi, Ministère de l'eau, de l'environnement, de l'aménagement du territoire et de l'urbanisme, op.cit, p.2.

6 Iwacu, Deuxième anniversaire du code foncier : des améliorations et des attentes », disponible sur $\mathrm{http}: / / \mathrm{www}$.iwacu-burundi.org/deuxieme-anniversaire-du-code-foncier-des-ameliorations-et-des-att entes/ (visité le 12 août 2013).

7 DE CLERK L., «La place de la coutume dans le droit actuel du Burundi », Revue administrative et juridique du Burundi, 1er trimestre 1968, n² 2, p. 31. 
puis belge ont fortement altéré le système traditionnel de gestion des terres ${ }^{8}$ par l'importation du droit Européen 9 .

Après l'indépendance, entre 1960 et 1980, (surtout à la faveur de la crise de $1972^{10}$ ), on assiste à l'instrumentalisation du droit par les élites politiques pour s'accaparer des biens fonciers des autres ${ }^{11}$. Avec le code foncier de 1986, le législateur Burundais a gardé l'illusion du colonisateur qui croyait au passage généralisé de la coutume au droit écrit en matière foncière, malgré le cout élevé de l'enregistrement ${ }^{12}$ et la forte centralisation du système ${ }^{13}$. La sécurisation foncière prévue par le code foncier de 1986 inspiré du système tor-

8 A la différence des colonies françaises ou britanniques, l'administration belge ne reconnaissait aucun droit à la propriété de droit civil aux sujets coloniaux. A l'exception des terres appartenant aux quelques rares Burundais immatriculés comme «évolués », les terres détenues par des Burundais étaient systématiquement considérées comme des terres domaniales, ce qui permettait à l'administration belge de les céder à tout moment à des colons, à des entreprises ou à l'Eglise (auxquels le droit à la propriété privée était reconnu). Le droit à la propriété privée ne fut accordé aux sujets coloniaux qu'en 1960, à la veille de l'indépendance, sans pour autant remettre en question les déséquilibres structurels entre dirigeants et dirigés dont se sont saisies les nouvelles élites politiques. Voir GAHAMA J., Le Burundi sous administration belge, (Paris, 1986).

9 Le Code civil livre II du Burundi intitulé : « Des biens et des différentes modifications de la propriété » était constitué par les décrets du Congo Belge du 30 juillet 1912, du 30 juin 1913, du 6 février 1920 et du 20 juillet 1920 rendus exécutoires au Burundi par l'ordonnance du Rwanda Urundi du 8 mars 1927, in Bellon R. et DELFOSSE P., Codes et lois du Burundi, Bruxelles, Maison Ferdinand Larcier, 1970, p.68 qui vont bouleverser la conception de la propriété foncière du Burundi précolonial. Pour plus de développements sur le sujet voir NIMPAGARITSE D.O, Organisation foncière et disparité des statuts immobiliers au Burundi, arrière plan historique, courbes de développements et nécessité d'intégrer un nouveau droit, Thèse, Bruxelles, 1983.

10 Des milliers de réfugiés Hutus ont été obligés de fuir vers les pays voisins laissant derrière leurs terres qui ont été occupés par les résidents qui ont eu l'occasion d'avoir des terres dont ils avaient besoin en raison de la pression démographique.

11 Le code foncier de 1986 de même que la législation coloniale antérieur ont été décriés comme des instruments de spoliations du passé. En effet, dès le départ de ces réfugiés, la réaction des autorités administratives locales, des chefs de cellules aux gouverneurs de province, a consisté à redistribuer leurs terres comme si celles-ci étaient simplement vacantes. Mais cette forme d'accaparement des terres n'a pas été un phénomène observable uniquement pendant les périodes de crise sociopolitique. Au Burundi, depuis l'indépendance, les officiels locaux s'attribuent des terres domaniales durant leur occupation du pouvoir. Jusqu'aujourd'hui, cette pratique n'a pas complètement disparue.

12 République du Burundi- Lettre de politique foncière de 2008, p5 : " L'enregistrement foncier exige des coûts auxquels la plupart des Burundais ne peuvent actuellement pas faire face. Elle implique la production d'une attestation d'identité, l'achat et le transport des bornes, le déplacement d'un géomètre et de son aide, la production d'un $P V$ d'arpentage et de bornage, le paiement d'une taxe communale et d'une contribution pour les indigents. Sans même tenir compte des surcoûts très importants - dus à la corruption, les dépenses à prévoir s'avèrent souvent trop élevées en regard du prix d'acquisition de la parcelle ».

13 République du Burundi- Lettre de politique foncière de 2008, p5 : «L'insuffisance de la déconcentration et l'absence de décentralisation rendent les services fonciers difficilement accessibles pour les usagers. Pour l'ensemble du pays, il n'existe que trois bureaux - à Bujumbura, Gitega et Ngozi - pour examiner des demandes et y faire suite $»$. 
rens ${ }^{14}$, certes plus protectrice a été un leurre et n'a pas produit l'effet escompté; car la procédure longue, très couteuse est restée inaccessible à la majorité de la population pauvre.

Quelques années après l'adoption du code foncier de 1986, on commence à constater des difficultés d'application surtout au niveau de l'enregistrement des droits fonciers ${ }^{15}$. La révision du code foncier était prévue par ailleurs au Protocole 4, article 8 (i) de l'Accord d'Arusha pour la paix et la réconciliation au Burundi du 28 août 2000 qui stipulait que : "Le Code foncier du Burundi doit être révisé afin de l'adapter aux problèmes actuels relatifs à la gestion des terres ». La nécessité de réviser le code foncier se reflétait également au niveau procédural. On sait que les litiges fonciers représentent $71,90 \%$ de toutes les affaires soumises aux cours et tribunaux ${ }^{16}$. Cette situation conflictuelle était aggravée par les litiges entre les rapatriés, rentrant dans leur pays, et ceux occupant « leurs parcelles historiques » que les résidents considèrent comme les leurs après l'usucapion de 30 ans.

Depuis le début des années 2000, une multitude de rapports sur la problématique foncière émanant d'Organisations Internationales et d'Organisations Non gouvernementales consacraient des formules telles que « la bombe foncière » et attiraient l'attention sur l'importance d'une bonne résolution des conflits fonciers comme gage pour la sécurité nationale ${ }^{17}$. Parmi ces conflits, nous distinguerons les conflits entre l'Etat et les personnes privées et ceux opposants des personnes privées entre elles.

La loi $\mathrm{N}^{\circ} 1 / 13$ portant révision du code foncier promulguée le 9 aout 2011 a suscité beaucoup d'espoir surtout que la population avait beaucoup d'attentes en ce qui est de la résolution des conflits fonciers.

14 En 1861, en Australie où cette loi a été mise en place par le Gouverneur d'alors, Sir Robert Richard TORRENS, la propriété foncière était d'origine récente. La Couronne britannique disponibilisa elle-même de larges moyens matériels et financiers pour couvrir les opérations de mesurage, de cadastrage, de bornage et de délivrance des titres fonciers à la suite de l'immatriculation des terres prises en possession par les colons. Ce système d'immatriculation offre à la propriété foncière une grande sécurité couverte par le titre de propriété délivré, une localisation parfaite ainsi qu'une grande facilité de transactions. Pour plus de développements voir NIMPAGARITSE D.O, Organisation foncière et disparité des statuts immobiliers au Burundi. Arrière-plan historique; courbes de développement; nécessité d'intégrer un nouveau droit, Thèse de doctorat spécial, Université Libre de Bruxelles, 1983, pp.482 et s.

15 KOHLHAGEN D., Vers un nouveau code foncier au Burundi?,? in l'Afrique des grands lacs. Annuaire 2009-2010, pp 67-98.

16 RCN justice et démocratie, Statistiques judiciaires Burundaises, rendement, délais et typologie des litiges dans les tribunaux de résidence, Bujumbura, décembre 2009, p.25. La question foncière est sociale et culturelle dans le sens que la terre n'est pas seulement une richesse économique mais un élément de la culture, une partie de la vie d'une famille et de son histoire. L'attachement à la terre est à ce point important que dans certaines régions les gens préféreraient vendre tout leur avoir pour ne pas perdre un procès foncier qui représente à la fois un point d'honneur et un défi familial. Voir NTAMPAKA C., Gouvernance foncière en Afrique centrale, Rapport FAO, 2008, p.5, disponible sur ftp://ftp.fao.org/docrep/fao/011/ak018f/ak018f00.pdf (visité le 10/08/2014).

17 INTERNATIONAL CRISIS GROUP(ICG), Réfugiés et déplacés au Burundi. Désamorcer la bombe foncière, Nairobi et Bruxelles, ICG, 2003. 
De plus la révision du code foncier a été mal comprise par la majorité de la population qui l'a confondue avec une réforme agraire impliquant une redistribution équitable des terres et une correction des injustices du passé notamment les spoliations foncières comme l'exprime bien KOLHAGEN :

"Les attentes liées à la réforme et les confusions sont nombreuses. Intervenu au moment du retour massif de réfugiés, le débat sur la nouvelle politique foncière porte tant sur une réforme à long terme que sur la nécessité de trouver des solutions d'urgence aux problèmes des rapatriés et de supprimer efficacement des préjudices causés en violation du code existant. Les risques - et les tentatives - d'instrumentalisation du débat s'ajoutent aux difficultés de compréhension que connaissent les questionnements parfois très techniques liés à la gestion domaniale et foncière».

C'est ainsi que les rapatriés et certaines victimes de la mauvaise gouvernance foncière avaient placé la barre des attentes très haute en espérant que la réforme va réparer les injustices du passé alors qu'en principe la loi dispose pour l'avenir.

Même actuellement la question foncière ne cesse d'être un sujet de débats, de passions, de conflits et surtout d'effusion de sang entre voisins et plus grave encore entre frères parents et enfants. C'est pour ces raisons que nous avons voulu chercher à savoir par cet article intitulé, "L'apport du nouveau code foncier en matière de résolution des conflits au Burundi », dans quelle mesure le nouveau code foncier a contribué à la résolution des conflits fonciers. Du point de vue méthodologique, nous allons consulter les textes juridiques régissant la matière, la doctrine et interroger la pratique.

L'article sera subdivisé en deux chapitres. Nous analyserons, dans un premier chapitre, l'apport du nouveau code foncier en matière de résolution des conflits entre l'Etat et les personnes privées et dans un deuxième chapitre, l'apport du nouveau code foncier en matière de résolution des conflits entre les personnes privées.

Chapitre I : l'apport du nouveau code foncier en matière de résolution des conflits fonciers entre l'Etat et les personnes privées.

Les conflits fonciers entre l'Etat et les personnes privées sont causés par la mauvaise gouvernance foncière et la problématique de l'expropriation pour cause d'utilité publique.

Section I : Apports du nouveau code foncier en matière de gouvernance foncière.

Parmi les conflits fonciers du Burundi figurent en premier lieu les conflits entre l'Etat et les particuliers causés d'abord par la non délimitation des terres relevant du patrimoine foncier de l'Etat ainsi que l'attribution abusive ou l'accaparement des terres de l'Etat par l'élite dirigeante. Le code foncier de 2011 a préconisé deux solutions pour diminuer ce genre de conflits à savoir l'inventaire des terres domaniales et la diminution du nombre des autorités 
compétentes pour attribuer les terres domaniales et la limitation de leur pouvoir d'appréciation par la mise en place d'un organe consultatif.

\section{$\S 1$. Inventaire des terres domaniales}

La non délimitation du domaine de l'Etat depuis l'époque coloniale jusqu'alors est problématique $^{18}$ car à la faveur de la pression démographique, la population a continué à occuper les terres de l'Etat supposées vacantes et y a implanté même des champs et des constructions. Ce qui fait que si l'Etat veut utiliser ces terres, la population demande l'indemnité d'expropriation alors que, à la faveur de cette non délimitation, l'Etat déclarerait ces terres sur base du principe de la présomption de domanialité des terres vacantes ${ }^{19}$ comme lui appartenant, pour échapper au versement de l'indemnité d'expropriation.

Le code foncier de 2011, contrairement à celui de 1986 qui se bornait à affirmer seulement le principe de la propriété de l'Etat sur les terres vacantes, a prévu, à son article 213, que :

"les terres du domaine privé de l'Etat doivent être mesurées, bornées, immatriculées au plan du cadastre national et enregistrées par les services en charge des titres fonciers $»$.

Ce qui est déjà un pas au niveau des prévisions légales. Le législateur Burundais a fait un pas en avant en confiant le travail d'inventaire des terres domaniales à la Commission nationale terres et autres biens à travers la loi $\mathrm{N}^{\circ} 1 / 01 \mathrm{du} 04$ janvier 2011 portant révision de la loi $\mathrm{N}^{\circ} 1 / 17$ du 4 septembre 2009 portant missions, composition, organisation, et fonctionnement de la Commission nationale terres et autres biens qui dispose en son article 5 que :

18 L'article 2 de l'ordonnance du 1 juillet 1884 du Congo Belge rendue exécutoire au Rwanda-Urundi par l'ordonnance du 8 mars 1927:« Nul n'a le droit d'occuper sans titre les terres vacantes ni de déposséder les indigènes des terres qu'ils occupent. Les terres vacantes doivent être considérées comme appartenant à l'Etat ». Mais l'administration coloniale s'est contenté seulement d'affirmer ce principe et n'a pas organisé une prise en possession systématique des terres qui après enquête de vacance devaient être délimités, enregistrés comme des terres de son domaine propre. Elle a pris l'option de prendre en possession les seules terres vacantes qui lui étaient nécessaire pour ses besoins immédiats. Les autres terres vacantes étaient frappées d'une présomption de domanialité. Par conséquent, L'administration coloniale Belge n'est pas parvenu à résoudre le conflit entre les droits de l'Etat et les droits des populations locales en départageant une fois pour toutes le domaine intangible de l'Etat et le domaine réservée à la population. Le principe de présomption de domanialité de l'Etat sur les terres vacantes posé par les Belges a été maintenu même après l'indépendance par le législateur. Même le nouveau code foncier le réaffirme à l'article 214 al.2: «Font notamment partie du domaine privé de l'Etat, tant qu'ils ne sont pas affectés ou réaffectés à un service ou à un usage public: les biens fonciers vacants et sans maître; (...)».

19 Les terres étaient jadis vacantes mais elles ne le sont plus car elles ont été continuellement occupées par la population. 
"La Commission est particulièrement chargée :- Mettre à jour, en concertation avec les services compétents, l'inventaire des terres de l'Etat, identifier et proposer la récupération de celles qui ont été irrégulièrement attribuées(...) ».

La mission d'inventaire a été accomplie par la CNTB bien que ce travail louable accompli est à la fois inconnu du public et mal apprécié ${ }^{20}$. Néanmoins, un problème de taille reste irrésolu, celui de l'arpentage, du bornage des terres domaniales alors que cela était une priorité ${ }^{21}$ pour éviter la poursuite de l'occupation de ces terres par les populations ainsi que leur attribution abusive.

Mr. Damien MACUMI, coordonnateur du programme national foncier, espère que :

"Avec l'aide de l'Union Européenne de 5,5 millions d'euros, le programme d'enregistrer les terres de l'Etat commencera en janvier 2014 et durera 4 ans (...). Grâce aux photos aériennes déjà disponibles, (...) les conflits entre la population et l'Etat burundais vont diminuer car toutes les terres seront identifiées $»^{22}$.

Même si l'appui financier était au rendez vous, ce qui n'est pas évident car jusqu'en octobre 2014, il n'a pas encore commencé, l'immatriculation des terres domaniales demande des moyens techniques et humains que le Burundi va difficilement mobiliser en raison de l'insuffisance de géomètres qualifiés.

Comme l'exprime bien le professeur Didace NIMPAGARITSE: cette enregistrement "s'accompagnerait forcément du recrutement et de l'entretien d'une " armée " de fonctionnaires, ainsi que d'un corps notarial très dense. Et le pays devrait d'abord envisager la formation de ces effectifs. Ces agents et cadres devront également être dotés d'un matériel technique et d'autres équipements à la hauteur de la mission qui ne serait plus confinée à quelques centres à vocation urbaine, mais qui couvrirait tout le pays $»^{23}$.

Aussi, faut -il la disponibilisation des moyens financiers, humains, techniques pour appliquer le code foncier en procédant à ce bornage, pour éviter de nouveaux conflits dans ce domaine.

20 Car masqué par le travail plus controversé de la CNTB en matière de résolution des conflits entre rapatriés et résidents.

21 Burundi, Note conceptuelle du secteur foncier, disponible sur : http://www.burundiconference.gov. bi/IMG/pdf/Note_conceptuelle_secteur_foncier.pdf.

22 Iwacu : Les terres de l'Etat : une ressource rare, des périmètres contestés, disponible sur http://ww w.iwacu-burundi.org/les-terres-de-letat-une-ressource-rare-des-perimetres-contestes(visité le 09/09/2014).

23 NIMPAGARITSE D., Organisation foncière et disparité des statuts immobiliers au Burundi. Arrière-plan historique; courbes de développement; nécessité d'intégrér un nouveau droit, Thèse de doctorat spécial. Université Libre de Bruxelles, 1983, pp.482 et s. 


\section{$\S 2$. Attribution de terres domaniales.}

I. Diminution du nombre d'autorités compétentes.

Le code foncier de 1986 fixait dans la section 2 du chapitre III, titre III intitulée « autorités compétentes » les règles gouvernant les catégories de terres domaniales pouvant faire l'objet de cession ou de concession ainsi que les autorités compétentes pour chaque catégorie. Ainsi, aux termes de son article 253 :

"Les terres du domaine privé de l'Etat sont, pour l'application de la présente section, classées comme suit:1er catégorie: terre rurale d'une superficie inférieure ou égale à quatre hectares; 2 e catégorie: terre rurale d'une superficie supérieure à quatre hectares et n'excédant pas cinquante hectares; 3e catégorie: terre urbaine d'une superficie inférieure ou égale à dix hectares; 4e catégorie: terre rurale d'une superficie supérieure à cinquante hectares; 5 e catégorie: terre urbaine d'une superficie supérieure à dix hectares ».

L'article 254 du code foncier de 1986 prévoyait que le gouverneur de province est compétent pour accorder la cession ou la concession d'une terre domaniale de la première catégorie; le Ministre ayant l'agriculture dans ses attributions, pour les terres de la deuxième catégorie, le Ministre ayant l'urbanisme dans ses attributions, pour les terres de la troisième catégorie. Il ajoutait que la cession ou la concession de terres de la quatrième et de la cinquième catégorie doit être, à peine de nullité, préalablement autorisée par un décret pris sur proposition du Ministre compétent ${ }^{24}$.

Au niveau de la catégorisation des terres domaniales le code foncier a diminué les catégories du code de 1986 et le nombre des autorités compétentes en matière de cession et de concession. En effet, l'article 221 du code foncier de 2011 classe les terres du domaine privé de l'Etat comme suit : $1^{\text {ère }}$ catégorie : terre rurale d'une superficie n'excédant pas vingt cinq hectares; $2^{\text {ème }}$ catégorie : terre rurale d'une superficie excédant vingt cinq hectares; $3^{\text {ème }}$ catégorie : terre urbaine d'une superficie n'excédant pas un hectare; $4{ }^{\text {ème }}$ catégorie : terre urbaine d'une superficie excédant un hectare. C'est en fonction de ces catégories que le législateur a déterminé les autorités compétentes en matière de cession et de concession. Le Ministre ayant les terres dans ses attributions est compétent pour une terre rurale d'une superficie n'excédant pas vingt cinq hectares; le Ministre ayant l'urbanisme dans ses attributions pour une terre urbaine d'une superficie n'excédant pas un hectare et le Président de la République par voie de décret après délibération en Conseil des ministres, pour les deux autres catégories de terres. Néanmoins, ces autorités compétentes ne peuvent, sous peine de nullité, céder ni concéder une terre domaniale non enregistrée ${ }^{25}$.La centralisation de ce pouvoir assorti de l'avis consultatif est un apport du nouveau code foncier dans la résolution des conflits futurs.

Article 222 du code foncier du Burundi. 


\section{Tableau synthétique de la diminution du nombre d'autorités compétentes}

\begin{tabular}{|l|l|l|l|}
\hline \multicolumn{2}{|l|}{ Code foncier de 1986 } & Code foncier de 2011 \\
\hline $\begin{array}{l}\text { Catégorie de terre } \\
\text { domaniale }\end{array}$ & $\begin{array}{l}\text { Autorité compétente } \\
\text { en matière de cession } \\
\text { et de concession }\end{array}$ & Catégorie de terre domaniale & $\begin{array}{l}\text { Autorité compétente en } \\
\text { matière de cession et } \\
\text { de concession }\end{array}$ \\
\hline $\begin{array}{l}\text { Terre rurale } \\
\text { d'une superficie } \\
\text { inférieure ou } \\
\text { égale à quatre } \\
\text { hectares }\end{array}$ & $\begin{array}{l}\text { Gouverneur de pro- } \\
\text { vince }\end{array}$ & $\begin{array}{l}\text { Terre rurale d'une superficie } \\
\text { n'excédant pas vingt cinq } \\
\text { hectares }\end{array}$ & $\begin{array}{l}\text { Le Ministre ayant les } \\
\text { terres dans ses attribu- } \\
\text { tions }\end{array}$ \\
\hline $\begin{array}{l}\text { Terre rurale } \\
\text { d'une superficie } \\
\text { supérieure à } \\
\text { quatre hectares } \\
\text { et n'excédant pas } \\
\text { cinquante hec- } \\
\text { tares }\end{array}$ & $\begin{array}{l}\text { le Ministre ayant } \\
\text { attributions }\end{array}$ & $\begin{array}{l}\text { Terre rurale d'une superficie } \\
\text { excédant vingt cinq hectares }\end{array}$ & $\begin{array}{l}\text { Le Ministre ayant l'ur- } \\
\text { banisme dans ses attri- } \\
\text { butions pour une terre } \\
\text { urbaine d'une superfi- } \\
\text { cie n'excédant pas un } \\
\text { hectare }\end{array}$ \\
\hline $\begin{array}{l}\text { Terre urbaine } \\
\text { d'une superficie } \\
\text { inférieure ou } \\
\text { égale à dix hec- } \\
\text { tares }\end{array}$ & $\begin{array}{l}\text { l'urbanisme dans ses } \\
\text { attributions }\end{array}$ & $\begin{array}{l}\text { Terre urbaine d'une superfi- } \\
\text { cie n'excédant pas un hec- } \\
\text { tare }\end{array}$ & $\begin{array}{l}\text { le Président de la Ré- } \\
\text { publique par voie de } \\
\text { décret après délibéra- } \\
\text { tion en Conseil des mi- } \\
\text { nistres }\end{array}$ \\
\hline $\begin{array}{l}\text { Terre rurale } \\
\text { d'une superficie } \\
\text { supérieure à cin- } \\
\text { quante hectares }\end{array}$ & $\begin{array}{l}\text { Le Président de la } \\
\text { République sur pro- } \\
\text { position du Ministre } \\
\text { compétent }\end{array}$ & $\begin{array}{l}\text { Terre urbaine d'une superfi- } \\
\text { cie excédant un hectare }\end{array}$ & $\begin{array}{l}\text { le Président de la Ré- } \\
\text { publique par voie de } \\
\text { décret après délibéra- } \\
\text { tion en Conseil des mi- } \\
\text { nistres }\end{array}$ \\
\hline $\begin{array}{l}\text { Terre urbaine } \\
\text { d'une superficie } \\
\text { supérieure à dix } \\
\text { hectares }\end{array}$ & $\begin{array}{l}\text { Le Président de la } \\
\text { République sur pro- } \\
\text { position du Ministre } \\
\text { compétent }\end{array}$ & \multicolumn{2}{|l}{} \\
\hline
\end{tabular}

Il sied de signaler en passant que le code foncier de 2011 a levé le flou sur la question des terres des paysannats qui constituaient encore des concessions selon le code de 1986. En effet, l'article 455 de code dispose :

"Les détenteurs de parcelles constitutives de paysannats dont leur occupation a été régulière et légale obtiennent la pleine propriété. (...)Tout litige qui naîtra de l'application de cet article sera réglé par la Commission foncière nationale ».

Ainsi les anciens concessionnaires sont devenus des propriétaires; mais la question des paysannats bien que tranchée est superposée à celle des conflits fonciers entre rapatriés et résidents; car ces terres situées dans la plaine de l'Imbo ont passé dans plusieurs mains à la 
faveur des crises du passé en particulier celle de 1972. La réponse aux conflits fonciers est tributaire de la solution des conflits entre rapatriés et résidents ${ }^{26}$.

\section{Création d'une Commission consultative : La Commission foncière nationale.}

Selon le code foncier de 2011, la cession ou la concession d'une terre doit être, à peine de nullité, accordée par l'autorité compétente après avis conforme de la Commission foncière nationale ${ }^{27}$. Cette commission doit être représentative des acteurs ayant un intérêt certain et actuel. Le décret mettant en place cette commission foncière a été signé le 31 décembre 2012 et ses membres ont été nommés le 1er avril 2013. La Commission donne son avis préalablement à la cession ou à la concession des terres domaniales, à l'expropriation foncière pour cause d'utilité publique. Elle peut également donner son avis sur toute autre question foncière que le Gouvernement peut lui soumettre. La Commission Foncière Nationale est dotée d'un Secrétariat Permanent ${ }^{28}$. Mais la Commission nationale foncière prévue à l'article 452 du code foncier risque de ne pas avoir l'efficacité voulue pour empêcher encore l'arbitraire dans ce domaine pour trois raisons :

- Primo, au niveau de sa composition, les membres de la Commission nationale foncière sont nommés par décret sur proposition du ou des Ministres ayant les terres dans leurs attributions. La commission nationale foncière est un organe complètement dépendant de l'exécutif car il serait difficile de croire que ses membres puissent donner un avis non conforme au Ministre qui a proposé au Président la nomination et qui sollicitent les avis conformes. Il ya à craindre qu'elle soit une caisse de résonnance de la décision des ministres. Par ailleurs ses membres travaillent à temps partiel à la commission mais restent fonctionnaires dans les ministères qu'ils représentent. D'où il faut pour que la Commission soit efficace lui donner l'autonomie organique.

- Secundo, au niveau de fonctionnement, la commission nationale n'a aucune autonomie financière et de ce fait ne dispose pas de budget de fonctionnement. C'est ainsi que son secrétariat permanent n'a pas encore été mis en place faute d'argent pour le rémunérer. L'absence d'autonomie financière handicape son fonctionnement car «C'est une structure qui demande beaucoup de moyens parce qu'on doit recruter un secrétaire permanent et des experts $»^{29}$. Le fait de lui priver des moyens de fonctionnement, n'est $-\mathrm{il}$

26 Plus de la moitié des conflits fonciers entre rapatriés et résidents se concentre dans la plaine de l'Imbo surtout que lorsque la personne se réfugiait abandonnant sa terre, cet abandon était considéré comme un manquement à l'obligation de mettre en valeur le paysannat concédé, motif à base duquel la terre était attribuée à une autre personne qui n'était pas parti en exil. Maintenant, les conflits naissent entre l'ancien concessionnaire parti en exil et le nouveau concessionnaire installé par l'Etat.

27 Article 223 du code foncier du Burundi.

28 Article 453 du code foncier du Burundi.

29 Iwacu, La commission foncière nationale, qui connaît? http://www.iwacu-burundi.org/la-commissi on-fonciere-nationale-qui-connait/(visité le 10/12/2013). 
pas un moyen de la contraindre à la soumission comme le dit le proverbe Burundais : « amaboko atanga yama ari hejuru y'ayakira » ce qui signifie littéralement les bras de celui qui donne sont toujours au dessus de ceux de celui qui reçoit (qui doit se courber pour bien recevoir).

- Tertio, par ailleurs certains ministres n'ont pas même pris l'habitude de demander leur avis. C'est par exemple au niveau de l'urbanisme, aucun dossier ne passe dans la commission pour qu'elle donne son avis préalablement alors que c'est là où il ya beaucoup d'attributions de terres domaniales et de possibles abus ${ }^{30}$. Nous rejoignons Mr. NDIKUMASABO Vincent quand il affirme avec raison que, "la commission doit donner préalablement son avis et les mesures prises par le ministre sans l'avis préalable de la commission sont réputées nulles. Au cas contraire, prévient-il, on retournerait dans l'ancien système monarchique où le chef pouvait donner n'importe comment une terre, d'où il doit y avoir des mesures $»^{31}$. L'état des lieux montre que des attributions illégales des terres subsistent surtout que certains ministres ont continué à donner des terres sans même les délimiter. D'où nous proposons à notre humble avis de renforcer son indépendance et par voie de conséquence son efficacité par :

- la révision des modalités de nomination des membres notamment par voie d'approbation parlementaire,

- l'octroie de l'autonomie organique et financière à la commission.

Section II. Apport du nouveau code foncier en matière d'expropriation pour cause d'utilité publique.

Le code foncier de 1986 était fortement critiqué en matière d'expropriation pour cause d'utilité publique car il a été constaté que parfois l'Etat abusait des expropriations notamment en expropriant des populations dans la périphérie des villes à Bujumbura pour redistribuer ces mêmes terres à d'autres personnes qui ont des moyens d'y construire des villas de luxe $\mathrm{e}^{32}$. Par ailleurs l'indemnité d'expropriation était insuffisante car elle n'avait pas été actualisée et n'était pas payée préalablement. Ce qui était une violation du droit national et international ${ }^{33}$.

30 Iwacu, La commission foncière nationale, qui connait? http://www.iwacu-burundi.org/la-commissi on-fonciere-nationale-qui-connait/(visité le 10/12/2013).

31 NDIKUMASABO V., cité par Iwacu, La commission foncière nationale, qui connaît? http://www. iwacu-burundi.org/la-commission-fonciere-nationale-qui-connait/ (visité le 10/12/2013).

32 Iwacu, «Le nouveau code foncier a apporté des améliorations » disponible sur http://www.iwacuburundi.org/le-code-foncier-a-apporte-des-ameliorations/ (visité le 5/09/2014).

33 En effet, le droit de propriété est un droit de l'homme par excellence consacré par la DUDH en son article 1, par la Charte Africaine des droits de l'homme et des peuples en son article 14.. Le droit de propriété est consacré par la Constitution du Burundi au titre des droits fondamentaux par l'article 36 de la Constitution qui dispose : «Toute personne a droit à la propriété. Nul ne peut être privé de sa propriété que dans les cas et de la manière établie par la loi et moyennant une juste et préalable indemnité ou en exécution d'une décision judiciaire coulée en force de chose jugée». 
Le code foncier de 2011 a apporté plusieurs innovations en ce domaine :

- Primo, en ce qui concerne le motif de l'expropriation, le code foncier de 2011 a clarifié que l'expropriation n'est permise que pour cause d'utilité publique. L'article $411 \mathrm{du}$ code foncier stipule que : «Le droit de propriété exercé en vertu d'un titre foncier, d'un certificat foncier, d'un titre administratif ou d'un mode coutumier d'acquisition, peut être exproprié pour cause d'utilité publique au bénéfice de l'Etat ou de toute autre personne publique, moyennant le versement d'une juste et préalable indemnité ${ }^{34}$. Ceci permet d'éviter les expropriations des paysans pauvres des abords des villes au profit des riches qui y construisent des villas.

- Secundo, pour éviter des expropriations arbitraires, le code foncier de 2011 prévoit que la mutation résultant de l'expropriation foncière doit être constatée dans un titre foncier établi par le Conservateur des Titres Fonciers, au vu de la décision de justice ou de l'acte constatant l'accord des parties et après paiement de l'indemnité d'expropriation ${ }^{35}$.

- Tertio, pour éviter le détournement du pouvoir d'expropriation le code foncier de 2011 prévoit que les biens expropriés ne peuvent être utilisés par le bénéficiaire de l'expropriation que pour la destination d'utilité publique énoncée dans la déclaration provisoire d'utilité publique et dans la décision d'expropriation ${ }^{36}$. Au cas contraire ils seront rétrocédés à leur ancien propriétaire en ces termes : "Si les biens expropriés pour cause d'utilité publique ne reçoivent pas cette destination dans les délais prévus par le projet final approuvé, et si aucune demande de prolongation n'a été introduite avant la fin desdits délais par le promoteur et approuvée, l'administration notifie aux expropriés la faculté qui leur est offerte de les reprendre et publie à cet effet un avis au Bulletin Officiel du Burundi $(. . .)^{37}$.

- Quarto, selon le code foncier de 2011, l'indemnité d'expropriation doit être fondée sur la valeur du bien exproprié appréciée de commun accord ou à la date du jugement. Elle doit être acquittée avant l'enregistrement de la mutation et au plus tard dans les quatre mois suivant l'accord amiable des parties ou la signification du jugement irrévocable y relatif. Passé ce délai, l'exproprié peut demander à l'autorité expropriante ou à la juridiction compétente l'annulation de l'expropriation, avec dommages-intérêts s'il y a lieu (article $453 \mathrm{du}$ code foncier de 2011). Pour les tarifs d'indemnisation, l'article $426 \mathrm{du}$ code foncier prévoit que les Ministres ayant les terres dans leurs attributions fixent par Ordonnance conjointe le niveau minimal des tarifs d'indemnisation des immeubles par nature et par incorporation, après avis de la Commission Foncière Nationale. Il en est ainsi de l'ordonnance ministérielle $\mathrm{n}^{\circ} 720 / \mathrm{CAB} / 304 / 2008$ du 20 mars 2008 portant actualisation

Comme l'exprime très bien la Constitution de la République du Burundi, le droit de propriété ne saurait être absolu. Mais cette privation ne peut avoir lieu que dans les conditions prévues par la loi.

34 Art. 411 de la Loi n ${ }^{\circ} 1 / 13$ du 9 août 2011 portant révision du code foncier du Burundi.

35 Article 413 du code foncier de 2011.

36 Article 414 du code foncier de 2011.

37 Article 414 du code foncier de 2011. 
des tarifs d'indemnisation des terres, des cultures et des constructions en cas d'expropriation pour cause d'utilité publique. Ces tarifs devraient être régulièrement actualisés mais cela n'a pas été fait, ce qui porte atteinte à la justesse de l'indemnité d'expropria$\operatorname{tion}^{38}$.

Le code foncier de 2011 respecte le droit à un procès équitable pendant toute la procédure; car, aux termes de l'article 428, les personnes expropriées peuvent également saisir la juridiction compétente pour contester le bien-fondé de l'expropriation, la consistance de l'indemnité ou le délai de déguerpissement. Le législateur a voulu de cette façon contrecarrer l'arbitraire ou l'abus de pouvoir des autorités compétentes en matière d'expropriation pour cause d'utilité publique.

Si les autorités respectaient les dispositions du code foncier de 2011, cela permettrait de rétablir la confiance des citoyens en leur administration foncière. Mais même aujourd'hui des conflits naissent dans ce domaine pour le non versement de l'indemnité d'expropriation $^{39}$ ou son insuffisance ${ }^{40}$. D'où des efforts pour la consolidation de l'Etat de droit restent à fournir.

\section{Chapitre II : l'apport du nouveau code foncier en matière de résolution des conflits fonciers entre les personnes privées.}

Les conflits fonciers entre les personnes privées sont liés à la contestation des droits fonciers successoraux de la femme, à l'insuffisance de la sécurisation foncière, sans oublier l'épineux conflit foncier des résidents et des rapatriés.

Section I. Apport du nouveau code foncier en matière de droits fonciers de la femme.

Théoriquement, les femmes comme les hommes ont droit à la propriété foncière. Au Burundi, la majorité de la population foncière accède à la propriété foncière par voie de succession, les autres modes d'acquisition de la propriété notamment l'achat, la prescription acquisitive, l'acquisition par voie de cession par l'Etat sont exceptionnelles.

Pratiquement, les femmes n'ont pas un droit d'accès facile à la propriété foncière car :

38 Ordonnance ministérielle $\mathrm{n}^{\circ}$ 720/CAD/304/2008 du 20 mars 2008.

39 La population dépossédée de ses biens immobiliers par le traçage de ce tronçon réclame des indemnités pour les pertes subie Voir l'article Iwacu, Construction de la route Nyamirambo-Buban$z a$ : les indemnités d'expropriation au cour des tensions.disponible sur http://www.iwacu-burundi. org/construction-de-la-route-nyamirambo-bubanza-les-indemnites-dexpropriation-au-coeur-des-te nsions/.

40 A Gatunguru, futur lieu de construction du palais présidentiel, les habitants se sont fortement opposés aux indemnisations insuffisantes selon eux. Iwacu, Gatunguru : un site, un palais et beaucoup de colère, http://www.iwacu-burundi.org/gatunguru-un-site-un-palais-et-beaucoup-de-colere/ (visité le 12/09/2014). 
"Dans les coutumes burundaises, les terres étaient détenues par des familles et non par des individus. Les hommes mariés géraient ces terres en tant que chefs de famille, mais cela impliquait pour eux des obligations et la nécessité de garantir un accès équitable (à la terre) aux femmes et aux hommes non mariés qui dépendaient d'eux. Dans la jurisprudence des tribunaux indigènes puis dans les tribunaux de l'État burundais, l'interprétation privatiste des droits fonciers coutumiers a conféré un droit exclusif aux chefs de famille $»^{41}$.

Or, telle que la coutume est interprétée par la jurisprudence de la plupart des tribunaux, les femmes ne détiennent pas de terres à titre individuel et ne jouissent donc pas de droit à l'héritage sur les parcelles appartenant à leur père que si elles ne sont pas mariées. Il n'y a d'exception que pour les biens fonciers se trouvant dans le milieu urbain pour lesquels la jurisprudence de la Cour suprême accepte que les femmes jouissent d'un droit égal à la succession.

Cette situation juridique est aujourd'hui dénoncée par de nombreuses organisations de défense des droits humains, telles que l'Association des Femmes Juristes du Burundi (AFJB) qui réclament une loi écrite consacrant l'égalité des sexes en matière d'héritages. Selon Jeanine Nkinabacura, coordinatrice de l'Association des Femmes juristes du Burundi

" le grand problème quant à l'accès de la femme à la terre réside toujours au niveau de la succession. En l'absence de la loi qui régit la succession, c'est la coutume qui s'applique alors qu'elle est discriminatoire vis-à-vis de la femme. Pourtant l'Etat burundais a ratifié plusieurs conventions qui parlent de l'égalité entre l'homme et la femme. Celles-ci font partie intégrante de la constitution. ${ }^{42}$

Néanmoins, il n'est pas évident que l'introduction du modèle occidental du droit des successions égalitaire puisse être véritablement acceptable aux populations rurales ${ }^{43}$. A notre humble avis, le code foncier aurait pu, sans toucher au domaine des successions, assimiler les terres à une forme de copropriété familiale. ${ }^{44}$ Ainsi, le partage des terres familiales ne serait pas interprété comme une succession mais comme le partage d'une copropriété. Mais la question est socialement et politiquement sensible à tel point que le Code foncier n'a pas voulu y apporter une quelconque innovation. Et ce n'est pas par hasard que ni le document de politique foncière ni le nouveau projet de code n'abordent le problème et que le projet de

41 KOLHAGGEN D., Vers un nouveau code foncier au Burundi? in l'Afrique des grands lacs. Annuaire 2009-2010, pp 67-98.

42 Iwacu, Les femmes sont discriminées, disponible sur http://www.iwacu-burundi.org/les-femmes-s ont-discriminees/ (visité le 1/12/2013)"

43 «Dans les milieux ruraux, il n'y a pratiquement plus rien à partager. Ainsi, il pense qu'introduire une nouvelle donne revient à déstabiliser les relations sociales : «Visiblement, les femmes des milieux ruraux ne veulent pas être à la base de cette déstabilisation. » Iwacu, Succession : l'absence de la loi discrimine les Burundaises disponible sur http://www.iwacu-burundi.org/succession-labse nce-de-la-loi-discrimine-les-burundaises/ (visité le 12/8/2014).

44 KOLHAGGEN D. 
loi sur les successions a été mis dans les tiroirs du gouvernement; ce qui ne décourage pas les associations féminines. Selon Anne-Spès NISHIMWE, coordinatrice de la CAFOB :

" même si le président de la République a empêché que cette loi soit évoquée, elle indique que les femmes ne vont pas renoncer, car l'objectif est d'avoir une base légale sur les successions et les régimes matrimoniaux. Par ailleurs, elle rappelle qu'il ne s'agit pas d'une loi pour les femmes, mais pour tout le monde. Elle ne va pas favoriser les uns au détriment des autres, car si une femme mariée hérite chez ses parents, c'est un plus pour son époux. ${ }^{45}$.

Ainsi, nous pensons que le législateur devait légiférer et lever le flou dans ce domaine, pour éviter les conflits fonciers qui déchirent le tissu social et les relations familiales.

Section II. Apport du nouveau code foncier en matière de sécurisation foncière.

Parmi les causes des conflits fonciers figure la difficulté pour la population de prouver son droit de propriété par un écrit émanant de l'administration qui est facilement opposable aux tiers. Le code foncier de 1986 avait dans la continuité de la législation coloniale opté pour le régime d'immatriculation. Le régime de l'immatriculation ou de l'enregistrement des terres mis en place au Burundi par l'Administration tutélaire belge et confirmé par le Burundi indépendant est directement inspiré par le « Real Property Act » de 1861 édicté par l'Autorité britannique en Australie et connu sous l'appellation de loi TORRENS ou de «TORRENS ACT » (du nom de son initiateur Gouverneur d'alors, Sir Robert Richard TORRENS). Etant donné que ce système exigeait des moyens humains techniques et financiers exorbitants, la Couronne britannique rendit disponibles de larges moyens matériels et financiers pour couvrir les opérations de mesurage, de cadastrage, de bornage et de délivrance des titres fonciers à la suite de l'immatriculation des terres prises en possession par les colons. Ce système d'immatriculation des terres, offrant à la propriété foncière enregistrée au Service des Titres Fonciers, une grande sécurité couverte par le titre de propriété délivré (« deed »), une localisation parfaite ainsi qu'une grande facilité de transactions permettant par ailleurs une large possibilité de crédit aux colons propriétaires fonciers ${ }^{46}$. Du jour de l'immatriculation foncière, le droit de propriété, matérialisé par le certificat d'enregistrement délivré, devient irrécusables et inattaquable en ce sens que ce certificat est doté d'une force probante très solide.

En s'inspirant de ce système, le législateur colonial tablait, au Burundi comme dans le reste des colonies, sur les avantages de sécurité, de confiance que le régime de l'immatriculation pourrait procurer aux colons, aux étrangers et aux rares Burundais proches des co-

45 Iwacu, Succession : l'absence de la loi discrimine les Burundaises disponible sur http://www.iwac u-burundi.org/succession-labsence-de-la-loi-discrimine-les-burundaises/ (visité le 12/8/2014).

46 Pour plus de précisions, voir Didace NIMPAGARITSE : Organisation foncière et disparité des statuts immobiliers au Burundi. Arrière-plan historique; courbes de développement; nécessité d'intégrer un nouveau droit. Thèse de doctorat spécial. Université Libre de Bruxelles, 1983, pp.482 et s. 
lons, qui avaient les moyens d'y accéder. En effet, à cette époque, les étrangers qui avaient des titres de propriété étaient plus protégés dans leurs propriétés foncières que l'écrasante majorité de Burundais incapables d'y accéder. Mais le législateur colonial et celui du code foncier de 1986 avaient sous-estimé les inconvénients et les obstacles auxquels allait se heurter ce système notamment la longueur et la lourdeur de la procédure ${ }^{47}$, le coût élevé des opérations du cadastre et de l'immatriculation, à charge d'une population pauvre ${ }^{48}$, la forte centralisation et les faibles performances des services publics chargés du cadastre et de l'immatriculation foncière ${ }^{49}$. Ainsi même après l'indépendance et jusqu'à l'adoption du code foncier de 2011, le régime d'immatriculation est resté l'apanage des rares privilégiés (élites politiques, intellectuels, commerçants) et la majeure partie des terres est restée sous le régime coutumier très vulnérable aux spoliations et aux abus constatés; d'où certains pensent que ce contexte a crée un climat favorable pour l'instrumentalisation du droit par les élites gouvernantes.

Le législateur de 2011 a aménagé un régime transitoire d'enregistrement allégé, " celui du certificat foncier », pour protéger les propriétaires coutumiers et stimuler les populations rurales à s'engager finalement sur la piste du régime de l'immatriculation que le monde rural continue d'ignorer. Ceci est une grande innovation du code foncier de 2011; mais faut-il interroger la pratique pour voir si la loi a eu les effets escomptés!

47 La procédure parait fort simple alors qu'elle est appelée à régir des situations compliquées. En effet, au Burundi surtout dans le monde rural, les droits fonciers sont souvent bien enchevêtrés c'est à dire que les populations continuent à user et à jouir en commun des parties du patrimoine foncier familial et les rapports juridiques en matière foncière s'entrecoupent et s'entrecroisent dans certaines de leurs parties, tandis qu'ils demeurent indivis dans certaines autres dépendances alors que le système de l'immatriculation de la propriété nettement individualisée, nécessite au préalable un partage général pour enregistrer une part individuelle. De plus, après le partage le morcellement et l'émiettement subséquent de la propriété foncière au rythme des naissances et des partages successoraux, nécessiteront des opérations d'immatriculation répétées pour le compte des nouveaux héritiers ou copartageants, et ces opérations vont constamment provoquer des refontes des propriétés déjà immatriculées. Les frais inhérents à l'immatriculation de ces fragmentations foncières successives augmenteront jusqu'à ce que les frais de l'immatriculation dépassent la valeur de la propriété foncière à immatriculer et à la longue, l'immatriculation se muera en une procédure stérile, très couteuse et économiquement défavorable. Pour plus de développements voir Didace NIMPAGARITSE : Organisation foncière et disparité des statuts immobiliers au Burundi. Arrière-plan historique; courbes de développement; nécessité d'intégrer un nouveau droit, Thèse de doctorat spécial, Université Libre de Bruxelles, 1983, pp.482 et s.

48 De plus,selon les informations recueillies auprès des Services du Cadastre et de la Conservation des titres fonciers, aussi bien à Bujumbura qu'à Gitega, tous les frais de déplacement, d'entretien et de séjour des géomètres sur le terrain, le coût des bornes et d'établissement des croquis, de même que les frais de délivrance du certificat d'enregistrement par le Conservateur des titres fonciers sont entièrement pris en charge par la personne qui sollicite l'immatriculation. Ce sont des dépenses énormes dépassant les ressources des populations rurales.

49 Les renseignements que nous avons recueillis auprès des services fonciers montrent le cadastre et l'immatriculation des seules zones urbaines absorbe pratiquement toute l'activité des géomètres du Service du Cadastre National avec ses trois antennes de Bururi, Gitega et Ngozi ce qui montre qu'il serait difficile de couvrir tout le territoire national. 
Le système de certification foncière auprès des services fonciers communaux a été bien accueilli par la population. Il sied de noter l'engouement de la population dans les communes où les services fonciers sont implantés pour sécuriser leurs droits et éviter des conflits fonciers.

Dans la Commune Nyabitsinda par exemple le chef du service foncier communal explique que : «cette forte demande s'explique par le fait que presque 95\% des habitants de cette commune ne sont pas natifs, cherchant à sécuriser leurs terres. ${ }^{50}$. Par ailleurs selon lui la Commune y trouve son compte au niveau des recettes : "cette mesure a augmenté les recettes car la plupart des demandeurs ont de vastes propriétés foncières allant jusqu'à 100 hectares.

Il est également heureux de noter que la question de superposition des droits successoraux a été résolue par la possibilité de certification collective prévue par le code foncier à l'article 380 en ces termes :

«Sont reconnus et protégés par la loi tous les droits réels exercés par toute personne physique ou morale de droit privé en vertu de la coutume ou d'un titre d'occupation délivré par l'autorité compétente sur des terres non domaniales, se traduisant par une emprise personnelle ou collective, permanente et durable, selon les usages $d u$ moment et du lieu et selon la vocation du terrain. Ces droits privatifs peuvent faire l'objet d'un certificat établi par le service foncier communal compétent territorialement ».

Le système de certification foncière auprès des services fonciers communaux souffre des insuffisances au niveau des textes d'application, parce que le cadre réglementaire d'application du CF n'a pas été mis en place. Dans les communes pilotes où il est entrain d'être expérimenté, il n'y a pas de cadre réglementaire approprié, on s'en remet aux dispositions générales de la constitution, de la loi communale ${ }^{51}$. La certification foncière fait face à des problèmes sérieux : la non implication de l'État. D'après Onésime NIKOBAGIRA, chef du service foncier de NYABITSINDA : «L'absence de l'initiative de l'Etat : ce sont des ONG et des OI qui expérimentent cela sans un cadre légal et dans un manque de coordination des divers acteurs $\|^{52}$ Il convient de signaler aussi la question de durabilité du service foncier communal : "le bailleur (Coopération Technique Belge) s'est désengagé à l'insu de l'administration communale(...) Le conseil communal a revu à la hausse les tarifs de de-

50 Iwacu, La certification foncière au service de la sécurisation des terres, disponible sur http://www.i wacu-burundi.org/la-certification-fonciere-au-service-de-la-securisation-des-terres/(visité le 01/04/2014).

51 En mai 2013, ces 24 services concernaient la plupart des provinces de Gitega, Karuzi et Ngozi, ainsi que certaines communes de Bubanza, Cankuzo, Muramvya et Ruyigi. Entretiens de Crisis Group, membres de l'unité de coordination du programme national foncier, Bujumbura, mai 2013.

52 Iwacu, La certification foncière au service de la sécurisation des terres, disponible sur http://www.i wacu-burundi.org/la-certification-fonciere-au-service-de-la-securisation-des-terres/(visité le 01/04/2014). 
mande d'inscription pour obtenir le certificat foncier en vue de couvrir les dépenses énormes relatives au fonctionnement du service foncier» ${ }^{53}$. S'il n'ya pas de durabilité, la population, après avoir obtenu le certificat foncier, risque de revenir aux actes de notoriété de l'ancien système. Il y a un risque non négligeable d'abus par l'administration communale; car les administrateurs qui devaient être formés en notariat pour remplir correctement leurs fonctions n'ont pas été formées. De même, les agents du service foncier communal n'ont pas été formés, à tel point que dans certaines régions du pays, ils empiètent sur le domaine de l'Etat notamment sur les servitudes prévues par le code de l'environnement, sans le savoir. C'est pour cela que DOMINIK KOLHAGEN affirme avec raison que

"Outre la volonté de changement proclamée au plus haut niveau, il importe de restaurer un climat de confiance à l'égard des autorités au niveau local. Lorsque l'administration communale est perçue comme un spoliateur potentiel, les raisons motivant des usagers à demander un certificat foncier sont nécessairement ambiguës. Or, dans de nombreuses localités, les accusations d'abus à l'échelle locale sont toujours nombreuses. Le risque est grand d'y enraciner un service qui sera, à terme, accusé des mêmes maux que les services fonciers préexistants. $"^{54}$.

Enfin, il faut trancher la question des droits successoraux de la femme pour éviter que la certification foncière ne vienne couronner l'injustice et ici nous rejoignons KOLHAGGEN quand il explique que :

"L'épineuse question de la succession des femmes n'a également pas été intégrée à la discussion, ni même les modalités de succession de manière générale. Toutes ces questions devraient maintenant être rapidement débattues avec des prises de décision claires afin d'éviter que le certificat foncier ne devienne un outil de plus pour cimenter des injustices sociales $»^{55}$.

Section III. Apport du nouveau code foncier en matière de résolution des conflits entre rapatriés et résidents.

Au Burundi, le phénomène des réfugiés, apparu dans les années 1960 à la faveur des crises sociopolitiques s'est accentué avec la crise de $1972^{56}$, qui marque le début d'un nouveau

53 Iwacu, La certification foncière au service de la sécurisation des terres, disponible sur http://www.i wacu-burundi.org/la-certification-fonciere-au-service-de-la-securisation-des-terres/(visité le 01/04/2014).

54 KOLHAGEN D., Commentaires sur la loi n ${ }^{\circ} 1 / 13$ du 9 août 2011 portant révision du code foncier du Burundi, 10 janvier 2012, p.2.

55 KOLHAGGEN D., Vers un nouveau code foncier au Burundi? in l'Afrique des grands lacs. Annuaire 2009-2010, pp 67-98.

56 Dans la soirée du samedi 29 avril (1972), des groupes armés, dont certains étaient venus de Tanzanie, attaquent les bourgades du sud du pays, massacrant systématiquement les fonctionnaires tutsi et leurs familles, s'en prenant aussi aux Hutu qui refusent de les suivre. Le récit de ces atroci- 
type de conflits lié à l'occupation des terres des réfugiés exilés, par les résidents, parfois avec la bienveillance de l'Etat représenté par l'administration locale ${ }^{57}$. La région de l'IMBO Sud (Nyanza Lac, Rumonge) où était concentré le gros des assaillants (donc, le principal théâtre des opérations) fut plus touchée, même si d'autres parties du pays ne seront pas épargné par la répression de l'armée. Les paysans Hutu, fuyant la répression, se réfugient alors par dizaines de milliers en Tanzanie, laissant derrière eux leurs propriétés ${ }^{58}$.

Ce phénomène allait se doubler d'un contentieux des terres; car la nature a horreur du vide. Très rapidement, en effet, les paysans venus des environs ou de plus loin ont occupé les terres des réfugiés avec bénédiction de l'Administration locale qui, au lieu de prendre des dispositions pour protéger les propriétés de ces expatriés dont le retour était prévisible, les ont plutôt attribuées comme s'il s'agissait de terres vacantes ${ }^{59}$. La tentation était d'autant plus grande qu'il s'agit de terres riches, déjà exploitées et habitées. A ces réfugiés se sont ajoutés ceux de la crise de 1993 mais pour eux le délai de 30 ans pour prescrire n'était pas atteint au moment de leur retour et ils ont repris leurs biens fonciers. Il n'en a pas été de même pour ceux de 1972. Ayant passé plus d'une trentaine d'années en exil avant de regagner leur patrie, ils se sont souvent vu contester tout droit sur leurs anciennes propriétés foncières, qui pouvaient constituer leurs seules sources de revenus et qui représentaient, pour beaucoup d'entre eux, leur unique identité officielle. Ce contentieux, qui aurait pu être réglé facilement en respectant les principes de base du droit est devenu au fil du temps un casse-tête politique et juridique car il a été instrumentalisé par les régimes successifs et risque de continuer à l'être si on n'y prend pas garde.

En effet, l'Etat Burundais (sous la deuxième République), confrontée au problème des terres des réfugiés promulgua le décret-loi relatif à la réintégration dans leurs droits des personnes ayant quitté le Burundi suite aux événements de 1972 et 1973 avec pour objectif "d'instaurer une procédure rapide spéciale pour apurer les contentieux des biens litigieux des rapatriés" 60 . L'article 2 de ce décret-loi créa une commission nationale des rapatriés qui, analysée de très près, a les attributions d'un tribunal spécial aux pouvoirs exorbitants ${ }^{61}$ car elle était saisie à la demande de toute personne intéressée et pouvait même, contrairement aux juridictions ordinaires, se saisir d'office. La saisine de la Commission dessai-

tés crée la panique en milieu tutsi. Le pouvoir militaire - policier noyauté par le " groupe de Bururi » qui fonctionne à l'ombre du président Micombero durant cette période lance aussitôt des représailles contre tous les leaders hutu et même contre tous les ressortissants de cette "ethnie " qui semblaient réussir socialement ». Pour plus de détails voir J.P. CHRETIEN et M. MUKURI, Burundi, la fracture identitaire. Logiques de violence et certitudes " ethniques », Karthala, Paris, 2002, p. 15.

57 Aristote en est venu à cette conclusion en constatant que la nature exige que tout espace soit rempli de quelque chose.

58 Il faut signaler que c'est la région la plus fertile du Burundi.

59 Alors qu'à cette époque, elle n'en avait pas légalement les prérogatives car le code foncier de 1986 qui prévoyait cette possibilité n'était pas encore promulgué.

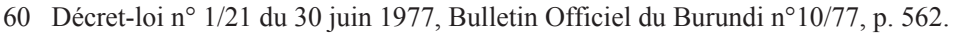

61 Décret-loi n 1/21 du 30 juin 1977, Bulletin Officiel du Burundi n¹0/77, p. 562. 
sissait la juridiction de droit commun préalablement saisie. Ensuite, exactement comme une juridiction, la Commission prenait une décision exécutoire non susceptible de recours « sauf par voie de tierce opposition par tout intéressé, non partie à la procédure, auquel elle(s) porte(nt) préjudice». Il est clair que le fonctionnement de la Commission et ses décisions violaient le droit à un procès équitable.

Ledit décret-loi a fragilisé les droits légitimes des rapatriés car

"...la procédure exigeait de déposer une plainte devant la commission en indiquant l'occupant illégal de la propriété réclamée ainsi que la taille de sa propre famille. La solution consista à partager la terre litigieuse entre l'occupant et le plaignant. Celuici était donc dépouillé d'une partie de sa terre en toute légalité. Bien plus, très peu d'anciens réfugiés rentrèrent à l'époque pour déposer plainte, de sorte que leur terre ne fut réclamée par personne. ${ }^{62}$.

Cette solution est toute à fait étonnante et contraire à la loi surtout qu'à cette période, il y avait à peine quatre ans que les réfugiés avaient quitté leurs propriétés et la simple application des règles de droit commun de la prescription aurait suffi à débouter les nouveaux occupants $^{63}$. Au lieu de résoudre le conflit une fois pour toutes, celui-ci s'est progressivement compliqué au fur et à mesure que les droits des nouveaux occupants se renforçaient, sans que pour autant la majorité des réfugiés rentre pour réintégrer leurs terres.

La IIIème République, elle aussi confrontée à ce problème ${ }^{64}$, créa par mimétisme une nouvelle Commission Nationale chargée du retour, de l'accueil et de l'insertion des réfugiés burundais qui malgré quelques spécificités ressemble étrangement à celle de la deuxième République $^{65}$. La Commission a effectivement fonctionné mais n'a pas pu avancer la ques-

62 International Crisis Group (ICG), Réfugiés et déplacés au Burundi : désamorcer la bombe foncière, Rapport Afrique ${ }^{\circ}$ 70, Nairobi/Bruxelles, 7 octobre 2003, p. 4.

63 L'article 647 du Code Civil livre III «Toutes les actions, tant réelles que personnelles, sont prescrites par trente ans sans que celui qui allègue cette prescription soit obligé d'en rapporter un titre ou qu'on puisse lui opposer l'exception déduite de la mauvaise foi ».

64 Le Président Buyoya avait initié la politique « de l'unité nationale » qui prônait le partage du pouvoir avec les membres de l'ethnie hutu qui, depuis la crise de 1972, avaient été pratiquement exclus du pouvoir : "La part des hutu dans le Gouvernement tutsi passa d'environ 20\% à la moitié » (J.P. Chrétien et M. Mukuri (sous la direction de), op.cit, p. 16.). C'est ce contexte qui a encouragé certains réfugiés à rentrer.

65 La nouvelle Commission était chargée d'une mission plus vaste. En ce qui nous concerne le contentieux des terres des réfugiés, elle avait pour mission de: "Aider les rapatriés à se réinstaller sur les propriétés encore disponibles et connaître du contentieux né à l'occasion des opérations de réinstallation"(art.1, b et c Décret-loi n 1/01 du 22 janvier 1991 portant création d'une Commission Nationale chargée du retour, de l'accueil et de l'insertion des Réfugiés burundais, Bulletin Officiel du Burundi n4/91 du 01/04/1991.). Par ailleurs, les attributions de cette Commission rappellent celles de la Commission précédente, notamment en ce qu'elle disposait des attributions d'une juridiction spéciale. Selon l'article 6, "Les décisions de la commission ont valeur de jugements coulés en force de chose jugée. Elles ne peuvent être attaquées que par voie de tierce opposition ». L'article 7 ajoute que la tierce opposition est portée devant la Commission qui décide de la suite à lui réserver. 
tion car le décret-loi de 1977 excluait déjà la possibilité de réinstallation sur des terres occupées et les conditions politiques n'étaient pas encore remplies pour un retour massif des rapatriés ${ }^{66}$.

Ce n'est qu'avec les élections démocratiques et la victoire du parti FRODEBU, à prédominance Hutu, que les choses changent: "Après le retour massif des réfugiés suite aux élections de 1993, la CNR intervint pour régler des différends fonciers à Rumonge. Mais aussitôt Ndadaye tué, les occupants illégaux retournèrent sur les terres spoliées ». Le parti FRODEBU réactiva la Commission du régime précédent et établit des antennes dans les administrations locales comme l'y autorisait le décret-loi de 1991 qui disposait, en son article 3 , que la Commission peut déléguer certaines tâches aux administrations locales. Sur base de la même loi qui protégeait les nouveaux occupants, ces derniers furent jetés à la rue et remplacés par leurs anciens prédécesseurs, ce qui causa une crise grave car les paysans, chassés par familles entières, investirent la Présidence de la République ${ }^{67}$. La question faillit causer une nouvelle guerre car les occupants chassés avaient des soutiens et des parentés dans l'armée qui était encore à cette époque acquise à leur cause. Le Président NDADAYE, voyant juste, défendit la thèse du respect des droits acquis lorsque le nouvel occupant n'avait pas plusieurs propriétés foncières : les réfugiés devaient s'installer ailleurs, sur des terres domaniales que l'Administration aménagerait à leur intention ${ }^{68}$.

Après la mort du Président NDANDAYE, les nouveaux occupants ont réalisé que même si les décisions de la Commission étaient inattaquables devant les juridictions ordinaires, il subsistait un moyen de les contester indirectement en invoquant l'inconstitutionnalité du Décret-loi instituant la Commission ${ }^{69}$. La Cour Constitutionnelle leur donna effectivement raison en ces termes:

"Attendu que, selon la Cour, la mission de rendre la justice est effectivement réservée aux seuls Cours et Tribunaux par l'article 140 de la Constitution; que, de fait, les conditions de recrutement et de nomination des magistrats des Cours et Tribunaux, leur organisation et leur mode de fonctionnement sont soumis à des règles particulières en vue d'assurer la compétence, l'impartialité et l'indépendance de la Magistrature; Attendu que l'organe créé par le Décret-loi précité est une simple Commis-

66 GATUNANGE G., Etude sur les pratiques foncières au Burundi - essai d'harmonisation - enquêtes menées dans 10 provinces du Burundi en février - mars 2004, p.20.

67 Selon International Crisis Group" En 1993, on vit des habitants de Minago manifester devant la Présidence de la République. Les maisons et les terres qu'ils occupaient (...) venaient d'être rendues à leurs propriétaires rapatriés, et ils juraient qu'ils ne quitteraient pas les lieux avant qu'on ne leur ait indiqué où aller », International Crisis Group, op.cit, p. 5.

68 Ce Rapporté dans Le Renouveau du Burundi, Dimanche 17 - Lundi 18 octobre 1993, p. 4.

69 En particulier l'article 6 du Décret-loi, qui stipule que les décisions de la Commission ont valeur de jugements coulés en force de chose jugée. En matière d'inconstitutionnalité, le système burundais permet à un particulier d'attaquer une loi soit par voie incidente, à l'occasion d'un litige devant les tribunaux ordinaires, soit par voie principale, en dehors de tout litige à condition de justifier d'un intérêt personnel. 
sion administrative; qu'elle ne présente pas, dès lors, les garanties d'indépendance et d'impartialité d'un organe judiciaire ${ }^{70}$.

Cette inconstitutionnalité rejaillissait sur les décisions rendues antérieurement par la Commission agissant en qualité de juridiction. On revint à la case départ de conflits non résolus. Cette question de l'inconstitutionnalité reste pleinement d'actualité, puisque l'Accord d'Arusha prévoit la création d'une Sous-commission ad hoc qui, à bien des égards, ressemble aux commissions précédentes ${ }^{71}$.

La question de ces conflits entre rapatriés et résidents est actuellement régie par la Loi $\mathrm{N}^{\circ} 1 / 31$ du 31 décembre 2013 portant révision de la Loi $\mathrm{N}^{\circ} 1 / 01$ du 04/01/2011 portant missions, composition, organisation, et fonctionnement de la Commission nationale terres et autres biens. Au début du rapatriement, la CNTB privilégiait la médiation, avec pour but le partage en deux de la terre entre le rapatrié et le résident ${ }^{72}$. D'aucuns accusent aujourd'hui la CNTB d'expulser purement et simplement les résidents sans aucune indemnité ni réinstallation sur une autre terre domaniale. La CNTB comme ses prédécesseurs a, par ailleurs, les pouvoirs d'une juridiction spéciale, en ce que ces décisions sont exécutoires nonobstant l'exercice de tous les recours ${ }^{73}$. Est-il acceptable du moins au niveau des principes qu'une décision exécutoire nonobstant toute voie de recours ne soit pas censurée par une juridiction ayant pour mission de dire le droit? N'est ce pas une nouvelle forme d'instrumentalisation du droit par l'élite au pouvoir? Enfin, au Burundi, ne serait- il pas admissible de tirer les leçons du passé pour éviter des voies sans issues, qui nous ramènent à la case départ? Après nous être posé ces questions, nous ne pouvons que rejoindre celui qui a affirmé que l'Histoire est un éternel recommencement. Selon Me Raphaël Gahungu, président du barreau de Gitega,

" le fonctionnement actuel de la CNTB ignore complètement la Constitution qui reconnaît aux seules juridictions le rôle de dire le droit et de procéder à son exécution.

70 Rôle de la Cour Constitutionnelle du Burundi (RCCB) n 31, 21 novembre 1994 (inédit).

71 Accord d'Arusha pour la Paix et la Réconciliation, 28 août 2000, Protocole V, Chapitre Premier, art. 3 b matérialisé par la Loi n ${ }^{\circ} / 017$ du 13 décembre 2002 déterminant les Missions, les compétences, l'organisation et le fonctionnement de la Commission Nationale de Réhabilitation des Sinistrés, Bulletin Officiel du Burundi n¹2/2002 p.1296 remplacé par la.

72 Ce qui n'était pas aussi conforme à la protection constitutionnelle du droit de propriété car il n'y avait pas de base légale à cette solution et aucune indemnité complémentaire pour compenser la partie de la terre perdue lors du partage n'était versée.

73 Article 19 de la loi portant organisation, missions, composition et fonctionnement de la CNTB "En cas de non règlement à l'amiable par la Commission, la partie intéressée peut saisir la juridiction compétente et la décision de la Commission reste exécutoire jusqu'à l'épuisement de toutes les voies de recours judiciaires $»$ ? Cette disposition toute à fait contraire à l'article 36 de la constitution du Burundi : "Toute personne a droit à la propriété. Nul ne peut être privé de sa propriété que dans les cas et de la manière établie par la loi et moyennant une juste et préalable indemnité ou en exécution d'une décision judiciaire coulée en force de chose jugée » qui consacre la protection constitutionnelle du droit de propriété dans le droit Burundais;. 


\section{Il indique que la commission a la mission de rétablir un climat de confiance entre les deux protagonistes et ainsi établir un climat de cohabitation pacifique $»^{74}$.}

Nous pensons qu'au lieu de perdre du temps, il faut chercher une solution à la base du droit au lieu de le contourner. Les décisions de la CNTB semblent violer le respect du procès équitable notamment en affirmant que parmi les occupants il n'ya aucun acquéreur de bonne foi(les résidents possesseurs étant présumés spoliateurs ${ }^{75}$, alors que en droit Burundais la présomption de bonne foi est un principe de base ${ }^{76}$. Par ailleurs se trouve posée la question de la responsabilité de l'Etat dans la gestion des confits fonciers ainsi que celle de la protection du droit de propriété de chaque catégorie (résident ou rapatrié) qui ne peut être restreint que moyennant indemnisation.

Pour sortir de ce cercle vicieux, des commissions changeant de nom mais ayant les mêmes limites, à savoir le fait de rendre des décisions administratives changeables selon le caprice du Prince qui les crée, le Gouvernement Burundais a choisi de créer une juridiction spéciale terres et autres biens par la loi $\mathrm{n}^{\circ} 1 / 26$ du 15 septembre 2014 portant création, organisation, composition, fonctionnement et compétence de la Cour Spéciale des Terres et Autres Biens ainsi que la procédure suivie devant elle ${ }^{77}$. Cette cour a pour mission de connaitre en dernière instance les recours contre les décisions prises par la $\mathrm{CNTB}^{78}$. Cette cour constitue une originalité jamais vue dans l'ordre judiciaire Burundais :

Primo, elle est une juridiction hyperspécialisée, car, auparavant, tous les recours dirigés contre les décisions de l'Etat étaient du ressort d'une juridiction spécialisée, la Cour administrative. Les décisions de la CNTB étant des décisions administratives sont désormais du ressort de la Cour spéciale terres et autres biens, juridiction spécialisée par rapport à la Cour administrative, elle-même spécialisée par rapport aux juridictions ordinaires.

Secundo, cette cour a pour mission de connaitre en dernière instance les recours contre les décisions prises par la CNTB. Elle comprend deux chambres: la Chambre de première

74 Iwacu, « On assiste à des décisions de la CNTB qui ignorent complètement la loi », disponible sur http://www.iwacu-burundi.org/on-assiste-a-des-decisions-de-la-cntb-qui-ignorent-completement-la -loi/(visité le 10/12/2013).

75 Iwacu, CNTB: «Pas d'acquéreur de bonne foi », http://www.iwacu-burundi.org/cntb-pas-dacquere ur-de-bonne-foi/(visité le 05 /09/2014.).

76 Article 22 du code foncier : "Celui qui acquiert de bonne foi un immeuble et en jouit d'une manière paisible, continue, publique et non équivoque pendant trente ans, en acquiert la propriété par prescription. Est réputé avoir acquis de bonne foi un immeuble quiconque a la croyance erronée mais non fautive en l'existence d'un droit foncier de la personne qui lui a cédé ledit immeuble. La bonne foi est toujours présumée et c'est à celui qui allègue la mauvaise foi de la prouver ».

77 Disponible sur http://www.assemblee.bi/Lois-promulguees-2014.

78 Article 2 de la loi $n^{\circ} 1 / 26$ du 15 septembre 2014 portant création, organisation, composition, fonctionnement et compétence de la Cour Spéciale des Terres et Autres Biens ainsi que la procédure suivie devant elle. 
instance et la Chambre d'appel ${ }^{79}$. Ceci est une innovation; car d'ordinaire, quand une juridiction rend un jugement, il appartenait à une autre juridiction de confirmer ou de réformer la décision. Après l'appel, la décision pouvait être attaquée devant la chambre de cassation de la Cour suprême. Ainsi, ses décisions ne sont pas susceptibles de recours devant une autre juridiction ${ }^{80}$, ni de cassation devant la Cour suprême, alors que celle-ci doit coiffer toute l'organisation judiciaire. Ce qui signifie que la juridiction aura des prérogatives dévolues à la Cour suprême. L'article 16 de la dite cour en disposant que : «Les décisions de la Cour sont exécutoires et ne peuvent être attaquées par voie d'opposition ou de tierce opposition » rappelle étrangement la compétence des commissions mis en place par la II ème et la IIIème République pour vider la question des terres des réfugiés ${ }^{81}$, sans pour autant y arriver.

Tertio, la saisine de la Cour entraine dessaisissement de la juridiction de droit commun $^{82}$ comme pour la Commission de la deuxième République. Pourquoi ne pas laisser la juridiction déjà saisie trancher? Espérons que c'est pour la bonne cause.

A notre avis, il serait présomptueux d'apprécier une institution avant de voir ses actes mais cette volonté de faire échapper d'emblée le contentieux foncier des juridictions ordinaires, que ce soit en première instance, en appel ou en cassation, risque de faire penser que la Cour spéciale terres et autres biens aura à appliquer d'autres règles spéciales que le code foncier; ce qui n'augure rien de bon. Il serait cependant sage de dire: attendons voir!

\section{CONCLUSION}

Le code foncier a apporté des innovations importantes en matière de résolution des conflits fonciers en mettant en place des dispositions qui améliorent la gouvernance foncière et en précisant les règles qui gouvernent l'expropriation pour cause d'utilité publique. Mais il faudrait garder un œil sur la manière dont la loi sera interprétée et appliquée par l'administration car les canons d'une coutume ne s'effacent pas par un décret loi.

Cependant le code foncier de 2011 n'a pas effleuré la question de succession de la femme qui subit une discrimination en matière successorale en violation de la Constitution Burundaise et des conventions internationales ratifiées par le Burundi. Si cette question

79 Article 4 de la loi n ${ }^{\circ} 1 / 26$ du 15 septembre 2014 portant création, organisation, composition, fonctionnement et compétence de la Cour Spéciale des Terres et Autres Biens ainsi que la procédure suivie devant elle.

80 Alors que le droit à un double degré de juridiction est un droit constitutionnel..

81 Selon l'article 6 de la Commission mise en place par la II ème République, "Les décisions de la commission ont valeur de jugements coulés en force de chose jugée. Elles ne peuvent être attaquées que par voie de tierce opposition ». L'article 7 ajoute que la tierce opposition est portée devant la Commission qui décide de la suite à lui réserver.

82 Article 100 de la loi $n^{\circ} 1 / 26$ du 15 septembre 2014 portant création, organisation, composition, fonctionnement et compétence de la Cour Spéciale des Terres et Autres Biens ainsi que la procédure suivie devant elle. 
n'est pas tranchée dans l'urgence, la loi viendra quand il n'y aura plus de terres à partager, en raison du morcellement accéléré des terres.

Le système de certification foncière mise en place par le code foncier de 2011 en faveur des populations rurales a le mérite de susciter l'engouement de la population. Mais l'Etat n'a pas mis en place les services fonciers communaux. Entretemps ce sont les organisations internationales et les organisations non gouvernementales qui les expérimentent dans les projets pilotes dans certaines communes avant que leur cadre légal complet soit mis en place. Ceci pose la question de leur durabilité car sans ces partenaires, soit le service foncier ferme les portes, soit on augmente les frais de certification, ce qui freine la certification. En permettant de sécuriser des terrains individuels de la taille d'un mouchoir de poche, on ne peut que se demander si le code ne crée pas plus de difficultés qu'il n'en résout en matière d'occupation des terres.

Or, il semble acquis au Burundi que toute réforme foncière pour être efficace devrait mettre un l'accent sur la régulation des conflits et intégrer une vision plus globale de la gestion des ressources naturelles. Reconnaissons toutes fois que les solutions au problème du morcellement excessif et des conflits fonciers ne pourront résulter que d'actions en dehors du régime foncier : limitation des naissances, création et multiplication de centres de métiers en milieu rural pour promouvoir des moyens de subsistance autres que l'activité agricole.

La question des conflits fonciers entre rapatriés et résidentsa révélé que des solutions non sérieusement mûries conduisent à un cercle vicieux qui les rafraichit au lieu de les résoudre définitivement. Pour cela on retourne à chaque fois à la case départ car les mêmes causes produisent les mêmes effets en matière d'instrumentalisation du droit. Nous pensons que toutes ces tentatives sont un moyen de faire échapper l'Etat Burundais à sa responsabilité à la fois dans les spoliations des biens des réfugiés que dans le traitement catastrophique de la question.

En effet, au lieu d'empêcher l'occupation des biens des réfugiés exilés à l'étranger et de ce fait incapables d'interrompre la prescription, l'Etat a fermé les yeux ou plus grave a encouragé les spoliateurs en leur octroyant même des titres. L'Etat a une obligation de respecter et de faire respecter le droit de propriété d'autrui, ce qu'il n'a pas évidemment fait or, " qui peut n'empêche pèche ». Au lieu de tourner en rond par des chemins sans issue, l'Etat Burundais devrait pour une fois avoir le courage d'assumer la responsabilité des erreurs du passées, car l'Etat reste unique, aujourd'hui comme hier. Une des pistes de solution serait la rétrocession des biens à leurs véritables propriétaires tout en indemnisant les acquéreurs de bonne foi ou en créant le fonds d'indemnisation prévue par l'Accord d'Arusha. Il pourrait partager la terre en deux et donner à chacun des protagonistes la moitié de l'indemnité pour la partie perdue en interprétant cela comme une expropriation partielle pour chacun. 


\section{BIBLIOGRAPHIE.}

A. Textes juridiques

1. Loi $\mathrm{n}^{\circ} 1 / 010 \mathrm{du} 18$ mars 2005 portant promulgation de la Constitution de la République du Burundi, in B.O.B 2005, pp. 1-35.

2. L'Accord de paix d'Arusha pour la paix et la réconciliation au Burundi, p18-19, in Codes et lois du Burundi, tome I, 2010, pp 28-54

3. La loi $\mathrm{N}^{\circ} 1 / 13$ du 9 aout 2011 portant révision du code foncier du Burundi.

4. Loi ${ }^{\circ} 1 / 008$ du 1er septembre 1986 portant Code Foncier du Burundi, Bulletin Officiel du Burundi $\mathrm{n}^{\circ} 7$ à 9/86.

5. Décret $n^{\circ} 1 / 21$ du 30 juin 1977, Bulletin Officiel du Burundi $n^{\circ} 10 / 77$.

6. Ordonnance Ministérielle $\mathrm{n} 720 / \mathrm{CAB} / 304 / 2008$ du 20 mars 2008 portant actualisation des tarifs d'indemnisation des terres, des cultures et des constructions en cas d'expropriation pour cause d'utilité publique

\section{B. OUVRAGES}

1. DE CLERK L., « La place de la coutume dans le droit actuel du Burundi », Revue administrative et juridique du Burundi, $1 \mathrm{er}$ trimestre 1968, $\mathrm{n}^{\circ} 2$.

2. GAHAMA J., Le Burundi sous administration belge, (Paris, 1986).

3. Bellon R. et DELFOSSE P., Codes et lois du Burundi, Bruxelles, Maison Ferdinand Larcier, 1970

4. NIMPAGARITSE D.O, Organisation foncière et disparité des statuts immobiliers au Burundi, arrière plan historique, courbes de développements et nécessité d'intégrer un nouveau droit, Thèse, Bruxelles, 1983.

5. J.P. CHRETIEN et M. MUKURI, Burundi, la fracture identitaire. Logiques de violence et certitudes " ethniques », Karthala, Paris, 2002.

6. H.COCHET, Crises et révolution agricoles au Burundi. 1993

7. J.P.CHRETIEN \& M.MUKURI, Burundi, la fracture identitaire : logiques de violences et certitudes ethniques. 2002

8. B.NDARISHIKANYE, Les rapports Etats-paysannerie au centre du conflit ethnique. In Cahier d'Etudes

\section{ARTICLES}

1. KOHLHAGEN D., Vers un nouveau code foncier au Burundi?,? in l'Afrique des grands lacs. Annuaire 2009-2010, pp 67-98

2. KOLHAGEN D., Commentaires sur la loi $n^{\circ} 1 / 13$ du 9 août 2011 portant révision du code foncier du Burundi, 10 janvier 2012. 


\section{RAPPORTS}

1. République du Burundi, Premier rapport de mise en application de la Charte Africaine des droits de l'homme et des peuples, Bujumbura, septembre 2010

2. NTAMPAKA C., Gouvernance foncière en Afrique centrale, Rapport FAO, 2008.

3. ICG (INTERNATIONAL CRISIS GROUP), Réfugiés et déplacés au Burundi. Désamorcer la bombe foncière, Nairobi et Bruxelles, ICG, 2003

4. International Crisis Group (ICG), Réfugiés et déplacés au Burundi : désamorcer la bombe foncière, Rapport Afrique $n^{\circ}$ 70, Nairobi/Bruxelles, 7 octobre 2003.

5. GATUNANGE G., Etude sur les pratiques foncières au Burundi-essai d'harmonisation - enquêtes menées dans 10 provinces du Burundi en février-mars RCN, 2004.

6. OBSERVATOIRE DE L'ACTION GOUVERNEMENTALE, Etudes sur la gestion des conflits sociaux liés à la gestion des terres et des propriétés foncières dans les sites de Kinyankonge, Nyabugete et Kamenge en Mairie de Bujumbura.

7. RCN-JUSTICE ET DEMOCRATIE, Etudes sur les pratiques foncières au Burundi. Mai 2004

8. REPUBLIQUE DU BURUNDI, Cadre Stratégique de Croissance et de Lutte contre la Pauvreté. Septembre 2006

\section{E. SITES INTERNET}

1. www.rfi.fr/afrique.

2. http://www.iwacu-burundi.org. 